\title{
Conocimiento de la educación, decisiones pedagógicas y decisiones de política educativa
}

\author{
J. M. TOURIÑÁN LÓPEZ \\ ANTONIO RODRÍGUEZ MARTÍNEZ \\ Universidad de Santiago de Compostela
}

\begin{abstract}
SUMMARY.-This article is engaged in upholding the appropiate place for decision in Educational Politics and Policy. All that inside the knowledge of Education.

Political decision making in the educational arena has got a place between technical decisions and moral decisions. The one has increased its relevance in educational forum. On the other point of view, this kind of decision must not be understood as a result of the discipline «Politics of Education» or as a consequence of practical theories which are known like «Politica Pedagógica» (Pedagogy into Politics).

Decisions in educational policy apply knowledge of Education but they are not made only with pedagogical facts and technical decisions. It's posible to think of technical decisions as the ones which come not only from the process, but from the knowledge of the process in its own.

Pedagogy as a discipline of education let you make technical decisions. Upper these ones, we find the moral decision. To study the special characteristics of political decisions shows two big mistakes into the controversy «Science-Moral-Politics»: scientism and moral subsunction of Political decision in that.

In the last pages, this work goes beyond the causal relation between «meansends». The authors suggest, for the field of goals, to make subsystem levels for decision making, in stead of ubing the taylorist model in order to organize beveral stages of goals.
\end{abstract}

1. El ÁMBITO DE LA RACIONALIDAD Y EL CONOCIMIENTO DE LA EDUCACIÓN INSTITUCIONALIZADO

La educación es un ámbito de realidad susceptible de ser conocido de diversas formas. La racionalidad científico-tecnológica, la racionalidad práxica, la racionalidad teológica y la racionalidad literaria y artística son dimensiones del conocimiento con peculiaridades propias que las hacen acreedoras del nombre formas de conocimiento (Hirst, 1974; Broudy, 1977; Touriñán, 1987a y 1989; Toulmin, Rieke y Janik, 1979). Son dimensiones del conocimiento, porque la extensión del criterio de conocimiento es en cada caso distinta. Son formas de conocimiento, porque cada una tiene sus conceptos distintivos; esos conceptos surgen en diferentes tareas y sus relaciones determinan las proposiciones significativas que pueden ser hechas en cada forma. Ni hablamos de la 
bondad moral de triángulo, ni de la expresión literaria del carbono. Cada forma de conocimiento tiene sus peculiares modos de prueba acerca de la verdad y validez de sus proposiciones.

La pedagogía como disciplina de conocimiento de la educación se incluye en la forma de conocimiento científico-tecnológico y tiene sentido, por tanto, decir que, ni todo conocimiento de la educación es conocimiento científico -existen otras formas de conocimiento-, ni todo conocimiento científico de la educación es Pedagogía entendida como disciplina de conocimiento -existen además teorías prácticas e investigaciones aplicadas-. El término Pedagogía, como disciplina de conocimiento, se reserva para la disciplina de la educación constituida por las teorías sustantivas y las tecnologías educacionales específicas. Así las cosas, para nosotros, no todo estudio científico de un ámbito es ciencia de ese ámbito, porque el estudio científico es un término más amplio que el de ciencia de un ámbito, ni todo conocimiento de la educación es constitutivo de la disciplina Pedagogía, pues hay otras disciplinas del conocimiento de la educación, por principio de definición. Unas y otras se construyen siempre con conocimiento de la educación que puede ser logrado de diversas formas (Touriñán, 1989; Touriñán y Rodríguez, 1993).

Las disciplinas científicas se constituyen en función de su objeto de estudio, es decir, de las características comunes al ámbito de la realidad específica que estudian con la forma de conocimiento científico-tecnológico. La física, la química, la historia, la biología, la sociología, la pedagogía, la economía, la psicología, etc., son disciplinas que se constituyen, epistemológicamente, dentro de la forma de conocimiento científico-tecnológico y que, ontológicamente, cubren ámbitos de realidad distintos (Bunge, 1981, pp. 25-26). Cada disciplina científica tiene autonomía funcional. Esta autonomía no es incompatible con la existencia de relaciones de dependencia entre disciplinas. Autonomía funcional quiere decir posibilidad de concebir un campo de conocimiento que se desarrolla, no como consecuencia de presiones y recomendaciones externas provenientes de otros campos dotados con estructura teórica consolidada, sino como resultado de regulaciones internas del propio campo de conocimiento, de tal manera que la teoría de ese campo quede limitada por los conceptos, hipótesis y metodologías del propio campo y no por las teorías de otros campos.

Ahora bien, autonomía funcional no equivale a defensa de absoluta independencia, es compatible con una fecunda relación interdisciplinar y con la defensa del principio de dependencia disciplinar. Cada una de esas disciplinas es disciplina científica, porque su modo de conocer su ámbito de estudio es la forma de conocimiento científico-tecnológica; y es autónoma, porque crea su propio campo conceptual y sus pruebas. Sus conceptos surgen del estudio específico del ámbito que analizan y las relaciones que descubren establecen qué proposiciones son significativas en cada disciplina.

Las disciplinas científicas se relacionan entre sí. La disciplina (A) puede usar a la disciplina (B) para sus investigaciones. Ahora bien, son autónomas, porque la validación de los conocimientos de la disciplina (A) no queda realizada por haber usado la disciplina (B), sino por las pruebas específicas de (A). La Pedagogía puede usar fórmulas matemáticas para establecer sus conclusiones; si falsea las pruebas matemáticas, las conclusiones pedagógicas serán falsas; pero, si no falsea las pruebas matemáticas, la validez matemática no garantiza las validez de la teoría pedagógica que depende de su propio sistema conceptual. Es el caso, por ejemplo, del uso matemático o físico de la 
igualdad e $=\mathrm{v} x$ t. Desde el punto de vista matemático, la igualdad de partida podría ser la combinación de las tres incógnitas: $\mathrm{e}=\mathrm{v} \times \mathrm{t} ; \mathrm{v}=\mathrm{e} \times \mathrm{t} ; \mathrm{t}=\mathrm{v} \times \mathrm{e}$. Cualquiera de las tres igualdades permite despejar sin error, $\mathrm{y}$, en cada caso, ' $\mathrm{v}$ ' sería distinto: $\mathrm{v}=\mathrm{e} / \mathrm{t}$; $\mathrm{v}=\mathrm{e} \mathrm{x}$ $\mathrm{t} ; \mathrm{v}=\mathrm{t} / \mathrm{e}$. Ahora bien, si a esas incógnitas matemáticas les damos significación desde los conceptos físicos, sólo hay un modo correcto de igualdad inicial: e = v x t. En este caso, es verdad que la validez matemática no garantiza la validez de la fórmula física que debe contrastarse desde su propio sistema conceptual, pero también es verdad que la validez matemática no puede alterarse para alcanzar conclusiones válidas en el otro ámbito disciplinar.

Las disciplinas científicas pueden desdoblarse en diferentes disciplinas académicas. Las disciplinas académicas se construyen por parcelación de la disciplina científica que las genera (la Pedagogía, la Historia, la Física, la Biología, la Psicología, etc.). Las disciplinas académicas son una concreción de la disciplina científica en una parcela de su ámbito de estudio que se produce como consecuencia del crecimiento de la disciplina científica.

Cada disciplina académica usa, epistemológicamente hablando, la forma de conocimiento que utiliza la disciplina científica y, ontológicamente, restringe su tarea de análisis al aspecto o parcela o sector que le incumbe de su disciplina científica generadora.

Cada disciplina científica y sus parcelas, las disciplinas académicas, son susceptibles de ser tratadas por la comunidad científica de tres modos distintos: como disciplina de investigación (investigación en la disciplina), como disciplina a investigar (investigación de la disciplina) y como disciplina a enseñar (asignatura de planes de estudios).

Cuando hablamos de la disciplina científica o académica como disciplina a investigar, estamos haciendo hincapié en la justificación y validación de la propia disciplina y de su sistema conceptual. Qué sea cada disciplina, es la cuestión en cada ámbito y es susceptible de sistematización como «investigación 'de' la disciplina científica».

Cuando hablamos de la disciplina científica o académica como disciplina de investigación, estamos significando la productividad y crecimiento de los conocimientos propios de la disciplina. La disciplina, en este caso, se identifica con el conjunto de investigaciones y con los productos de las mismas; es el trabajo de investigación «en y desde» la disciplina. De acuerdo con esta distinción, podemos decir que:

a) Los contenidos de una disciplina académica sustantiva se validan por coherencia con la investigación de la disciplina, es decir, por coherencia con la concepción del campo.

b) Los contenidos de una disciplina crecen por productividad o crecimiento simple de la concepción del campo y de acuerdo con el desarrollo de la investigación en la disciplina.

Cuando hablamos de la disciplina científica o académica como disciplina a enseñar, estamos significando su acondicionamiento a un plan de estudios concreto, dentro de una carrera específica. Como disciplina a enseñar, la disciplina científica se convierte en asignatura.

Las posibilidades de división de disciplinas y de creación de asignaturas en planes de estudio obedece en muchos casos a razones pragmáticas, ajenas al criterio ontológico y epistemológico que hemos manejado al hablar de los límites de identidad de las disciplinas académicas. En cualquier caso, el nivel escolar en el que se imparte la asignatura, la competencia del profesor y el tiempo son condicionantes específicos de las asignaturas de planes de estudios (Celorrio, 1993; Torroba, 1993; Pérez Juste, 1993): 
Cada asignatura se identifica con la organización curricular de la disciplina para un tiempo dado y un plan de estudios concreto, en orden a la enseñanza y al aprendizaje de determinados conocimientos consolidados en la disciplina. Es frecuente que cada asignatura de plan de estudios responda sólo a una parte de la temática consolidada en la disciplina académica sustantiva (la competencia del profesor, el lugar de la asignatura en la organización vertical del plan de estudios y el tiempo de docencia, son factores condicionantes). Precisamente por ello, existen universidades en las que la disciplina académica sustantiva se responde desde una, dos o tres asignaturas del plan de estudios. Son condiciones de tipo institucional y administrativo las que parcelan el contenido de la disciplina en asignaturas. Este tipo de condiciones es el que permite razonar acerca de la presencia suficiente o insuficiente de la disciplina académica en el plan de estudios y de la buena o mala articulación de la misma en el plan, según el lugar que se le otorgue a las asignaturas de esa disciplina en aquel.

Cada asignatura de plan de estudios se identifica con una parte del contenido de la disciplina académica y se justifica con razones pragmáticas, de tiempo, lugar en el plan de estudios y preparación del profesor, así como por los objetivos del plan de estudios. Esto es así porque, de acuerdo con las tesis expuestas, puede mantenerse respecto de cualquier relación de contenidos de asignatura de plan de estudios lo siguiente:

1. Los contenidos de una asignatura de plan de estudios no se corresponden necesariamente con los contenidos de una disciplina académica sustantiva. Por razones pragmáticas, que hemos visto ya, pudieran existir dos o tres asignaturas que repartan el contenido de la disciplina académica sustantiva.

2. Los contenidos que se enseñan en una asignatura de plan de estudios son aquéllos que, no sólo están avalados por la investigación de y en la disciplina científica, sino que además responden a los objetivos de la disciplina y del curso dentro del plan de estudios.

El conjunto de asignaturas que tiene que estudiar el alumno en un plan de estudios, a fin de lograr el conocimiento requerido para alcanzar su graduación, se identifica genéricamente como carrera. Y, de ese modo, puede decirse que, desde las diversas formas de conocimiento que son susceptibles de aplicarse al ámbito de realidad de la educación, se construyen los conocimientos de la educación -entre ellos la Pedagogía-; ésta, junto con las demás disciplinas de conocimiento de la educación, convertidas en asignaturas, tiene un lugar determinado en los planes de estudios de la carrera de Pedagogía.

Tiene sentido hacer esta introducción acerca de la institucionalización de las diversas formas de conocimiento aplicables a la educación, porque vamos a hablar de decisiones pedagógicas y de decisiones de política educativa en este trabajo y ambos tipos de decisión no responden al mismo ámbito de racionalidad, aunque tienen que ver con el conocimiento de la educación y con la carrera de Pedagogía.

En nuestra opinión la Política de la Educación es una disciplina académica del conocimiento de la educación. Es una teoría interpretativa de un ámbito de realidad: la educación. La Política de la Educación como interpretación del ámbito de realidad 'Educación', en la misma medida que se relaciona con metas de la educación, social y moralmente sancionadas como valiosas, permite establecer reglas que dirigen la acción de intervención para lograr esas metas. Este tipo de reglas, es lo que se conoce como Política Pedagógica, que es la teoría práctica derivada de la Política de la Educación como teoría interpretativa. Este tipo de reglas, junto con las metas que se pretenden lograr, 
SISTEMÁTICA DE DISCIPLINAS

DE LA EDUCACIÓN

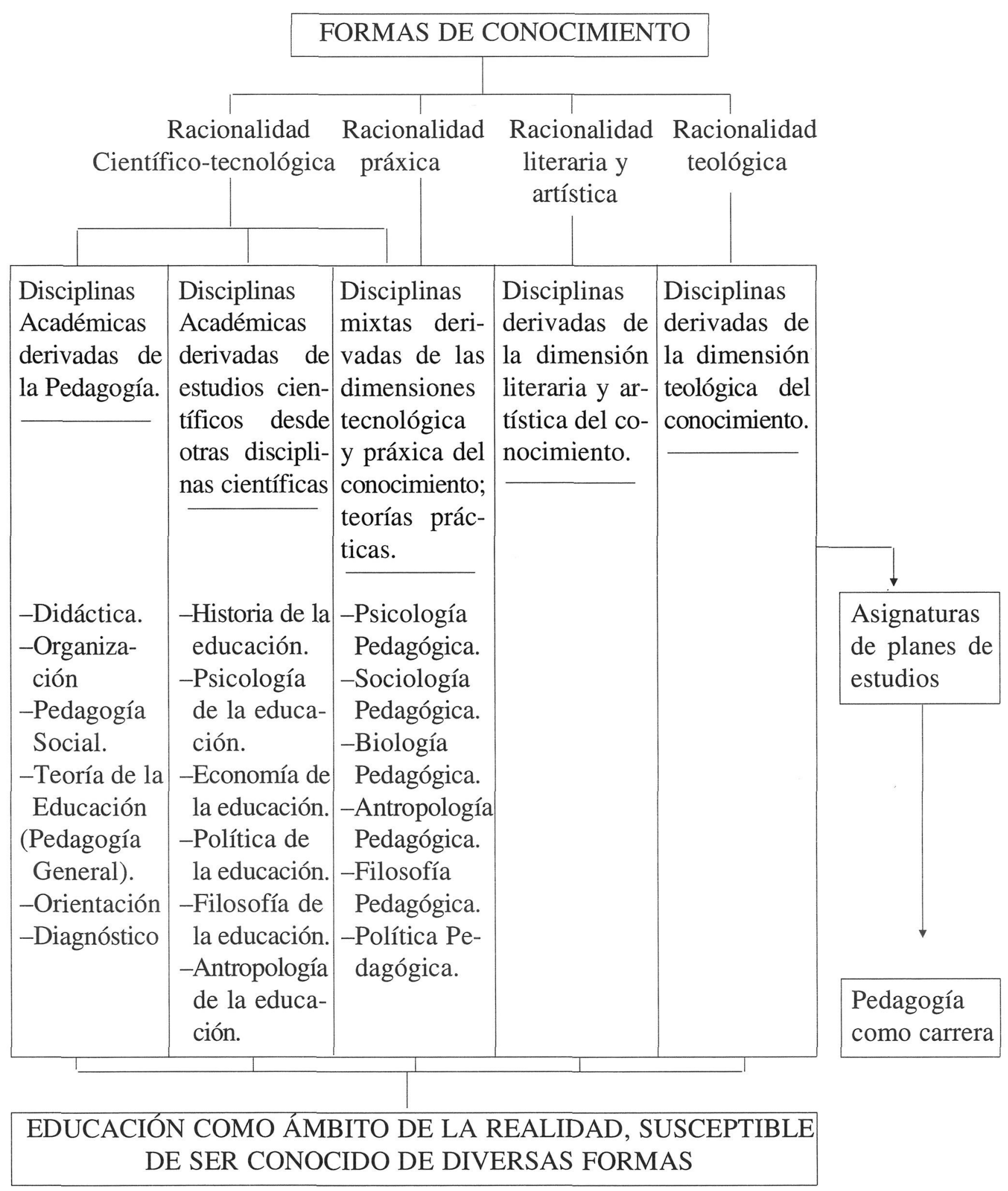

forman parte del conjunto conocido en su realización como política educativa concreta de un país. Las decisiones de política educativa exigen establecer las prioridades de acción política en el marco de la educación y los modos de lograr esas prioridades. Las 
decisiones pedagógicas se construyen a partir de los hechos pedagógicos. Unas y otras, decisiones de política educativa y decisiones pedagógicas, se construyen contando de forma distintiva con el conocimiento de la educación y apelando a supuestos diferentes, como vamos a ver a continuación (Touriñán, 1987 y 1989: Rodríguez Martínez, 1989).

\section{LA POSIBILIDAD DE HECHOS Y DECISIONES PEDAGÓGICAS}

\subsection{El carácter axiológico de los hechos}

Hablamos de hechos y decisiones pedagógicas, y esto quiere decir que del mismo modo que los profesionales de la Psicología, Sociología, etc., establecen qué cosas son hechos de su ámbito y cuales son procesos de toma de decisiones técnicas, el profesional de la educación debe estar en condiciones de establecer hechos y decisiones de su propio ámbito.

Ante un determinado suceso, evento o acontecimiento, el científico desarrolla todo un proceso de elaboración para relacionar sus afirmaciones con la realidad que expresan. Ese proceso de elaboración exige establecer ciertas cosas de lo sucedido -del acontecimiento- como hechos científicos de su ámbito que garantizan la verdad de lo que afirmamos acerca del acontecimiento (Ferrater, 1979, pp. 1447-1450).

En un sentido primario es cierto que 'hecho' es todo lo que sucede o acontece (Russell, 1977, p. 155). Ahora bien, en un sentido técnico, los hechos tienen una significación más precisa; los hechos científicos son construcciones organizadas que garantizan la credibilidad del contenido de las proposiciones que hacemos acerca de los acontecimientos (Touriñán, 1987).

Esto es así porque, la imagen que nos hacemos de las cosas, no es en absoluto reduplicativa; toda imagen selecciona necesariamente ciertos aspectos del original. Los estudios actuales de la percepción permiten afirmar que, si bien es verdad que lo que vemos está relacionado con las imágenes de nuestras retinas, también es verdad que otra parte muy importante de lo que vemos está relacionado con el estado interno de nuestras mentes, nuestra educación, nuestro conocimiento y experiencias y nuestras expectativas (Chalmers, 1982, pp. 40-46).

Es obvio que esto no quiere decir que no podamos ver distintas personas la misma cosa; por una parte el argumento nos sirve como prueba de que la imagen que nos hacemos de las cosas no es reduplicativa, y, por otra, nos sirve para comprender que los hechos científicos están elaborados, porque nuestras experiencias directas e inmediatas no son la garantía de credibilidad del contenido de las proposiciones que hacemos acerca de los acontecimientos.

Popper -creador de los principios defendidos por el racionalismo crítico- mantiene dos tesis básicas que sostienen el carácter de los hechos científicos:

a) La improcedencia de confiar en las experiencias observacionales directas e inmediatas.

b) La defensa de los hechos científicos como construcciones afectadas de carga teórica.

Respecto de la primera tesis nos dice Popper lo siguiente: 
«Desde el punto de vista aquí establecido hemos de rechazar como totalmente infundada toda epistemología subjetivista que pretenda elegir como punto de partida eso que a ella no le parece en absoluto problemático; es decir, nuestras experiencias observacionales 'directas' o 'inmediatas'. Hay que admitir que, en general, estas experiencias son perfectamente 'buenas' y 'eficaces', pero no son ni directas, ni inmediatas, ni mucho menos fiables» (Popper, 1974, p. 75).

Todo el que busca un conocimiento absolutamente seguro tiene que basar sus criterios en la creencia -lo cual es difícil de defender racionalmente- o en la revelación por medio de los sentidos, en el entendimiento de que esa pureza del origen garantiza la liberación del error. Sin embargo, frente a estas concepciones hay que defender el carácter 'espurio' de esos criterios. Todo biólogo admitirá que nuestros órganos sensoriales son eficaces la mayoría de las veces, pero negará que sean eficaces siempre y que podamos confiar en ellos como criterios de verdad (Popper, 1974, p. 79):

«La base empírica de la ciencia objetiva, pues, no tiene nada de 'absoluta'; la ciencia no está cimentada sobre roca; por el contrario, podríamos decir que la atrevida estructura de sus teorías se eleva sobre un terreno pantanoso, es como un edificio levantado sobre pilotes. Estos se introducen desde arriba en la ciénaga, pero en modo alguno hasta alcanzar ningún basamento natural o 'dado'; cuando interrumpimos nuestros intentos de introducirnos hasta un estrato más profundo, ello no se debe a que hayamos topado con terreno firme; paramos simplemente porque nos basta que tengan firmeza suficiente para soportar la estructura, al menos por el momento» (Popper, 1977, p. 106).

Respecto de la segunda tesis, Popper mantiene que las observaciones, es decir, lo que nosotros referimos de los acontecimientos en los enunciados básicos -que son los que constituyen la base de credibilidad de la ciencia-, no son hechos puros, es decir, cosas sucedidas o acontecimientos, sino aspectos significativos y seleccionados de los mismos. Las observaciones «son siempre interpretaciones de hechos observados, no hecho puros; es decir, son interpretaciones a la luz de teorías» (Popper, 1977, p. 103).

En el racionalismo crítico los acontecimientos ocurren simplemente, pero se convierten en hechos significativos por convención, por acuerdo intersubjetivo. Evidentemente contrastamos los enunciados básicos, pero sólo nos dedicamos a observar aquello que es significativo para contrastar y falsear nuestra teoría.

«Los enunciados básicos se aceptan como resultado de una decisión o acuerdo, y desde este punto de vista son convenciones. Por otra parte, se llega a las decisiones siguiendo un proceder gobernado por reglas; y entre éstas tiene especial importancia la que nos dice que no debemos aceptar enunciados básicos esporádicos - es decir, que no estén en conexión lógica con otros enunciados-» (Popper, 1977, p. 101).

Sólo en la medida que nos ponemos de acuerdo en los enunciados básicos estamos en condiciones de transformar una colección de contenidos en una disciplina científica. Toda la ciencia necesita un punto de vista y problemas teóricos. Los partidarios de la concepción heredada creen que el camino de la ciencia consiste en «recopilar y ordenar nuestras experiencias, y que así vamos ascendiendo por la escalera de la ciencia (...) que si queremos edificar la ciencia tenemos que recoger primero cláusulas protocolarias» (Popper, 1977, p. 101). Lo cierto es que nadie sabría como dedicarse a registrar lo que está experimentando en un momento sin una teoría (Popper, 1977, p. 101). 
Cabe decir, por tanto, que en la investigación científica, desde las tesis del racionalismo crítico, los hechos científicos están afectados de carga teórica, es decir, están valorados como adecuados para explicar los acontecimientos (Koertge, 1982; y, Radnitzky, 1982).

Por consiguiente, si no hay una certeza absoluta en la base empírica de la ciencia y nuestras observaciones son interpretaciones a la luz de teorías, se sigue que los hechos no son 'aproblemáticos', sino afectados de carga teórica (Taylor, 1976).

Adviértase que de la afirmación anterior no se sigue que las teorías científicas sean inconmensurables. Si bien es verdad que algunos autores han pretendido tal conclusión anárquica (Feyerabend, 1981), debe quedar bien claro que las consecuencias derivadas del carácter axiológico de los hechos científicos no supone necesariamente el abandono del principio científico de ajustarse a la realidad.

En defensa de ese principio, Toulmin (1977 y 1974) insiste en la necesidad de aceptar que, si los hechos están afectados de carga teórica y la meta de la investigación es construir una representación mejor de la realidad y procedimientos explicativos mejores, no puede mantenerse que los sistemas formales de proposiciones o los acuerdos en los enunciados básicos brinden las únicas formas legítimas de explicación científica:

«La racionalidad de la ciencia tiene menos que ver con la sistematicidad lógica o con la autoridad supuestamente indiscutible de cualquier cuerpo de ideas o proposiciones, que con la forma en que los hombres abandonan un cuerpo de ideas o conceptos científicos a favor de otro o con las consideraciones a la luz de las cuales se disponen a hacerlo» (Toulmin, 1974, p. 405).

El carácter axiológico de los hechos científicos permite entender sin dificultad que cada científico en su ámbito establece objetivamente las relaciones pertinentes. Un hecho biológico no es cualquier tipo de hecho científico, porque el biólogo se ha ocupado en delimitar y contrastar los enunciados que le permiten afirmar la pertenencia de determinados hechos en su ámbito. En la misma medida que su conocimiento avanza, no sólo puede atribuir valor biológico a más cosas, sino que, además, cabe la posibilidad de que lo biológico se defina de otra manera más ajustada a la posible explicación de la realidad. El conocimiento no tiene, como hemos visto, garantía absoluta de certeza. En este sentido, el valor de los datos se mejora. No se trata de que elijamos cosas distintas en momentos históricos distintos (hoy no es frecuente elegir el carro como transporte, aunque no negamos su valor), se trata más bien de reconocer que, al redefinir el ámbito de pertenencia, los objetos que en un momento se valoraban -se eligiesen o no - pueden perder su significación. Es en ese sentido y no en otro en el que me parece que debe entenderse que el marco teórico restringe las posiciones de valor que justificadamente puedan defenderse (Taylor, 1976, p. 165).

La propia organización intelectual configura el campo de investigación de tal manera que el marco apunta con precisión a lo que debe explicarse.

Entre hechos científicos y acontecimientos hay una relación que acabamos de ver. Y si no olvidamos que la organización intelectual del ámbito condiciona los hechos científicos de ese ámbito es posible afirmar que en una mentalidad pedagógica subalternada, que niega significación propia a los conceptos educacionales, hablando con precisión, sólo existirían hechos educativos, y hechos psicológicos, sociológicos, etc., según cual sea la disciplina generadora desde la que interpretamos y damos significado a la educa- 
ción. Pero por la misma razón, puede decirse que, hablando con propiedad, los hechos pedagógicos corresponden sólo a la mentalidad pedagógica de la educación que considere a esta como ámbito de realidad con significación intrínseca, es decir, capaz de ser interpretado en conceptos propios de ese ámbito.

De acuerdo con la exposición realizada, el acontecimiento se convierte en hecho pedagógico significativo a la luz de la teoría. Es el propio marco teórico el que nos dice qué es lo que debe ser explicado, porque existe el carácter axiológico de los hechos. Pero, además, los hechos tienen que contrastarse. Representamos el acontecimiento en conceptos, pero no consideramos aceptable esa representación, si no supera las condiciones de prueba. Desde el punto de vista del descubrimiento, la teoría presupone el conocimiento de ciertos acontecimientos. Desde el punto de vista de la justificación, la teoría precede a los hechos y dirige su producción.

Pero, por otra parte, el carácter axiológico de los hechos tiene especial interés porque, de ese modo, el científico puede legitimar las orientaciones de su acción técnicamente desde su propio ámbito de competencia.

\subsection{La orientación de la acción desde los hechos}

La tesis de que las cuestiones referidas a los fines de la acción son ajenos a los procedimientos de la racionalidad científica tiene su origen en un texto de Hume:
"En todos los sistemas de moralidad que se han encontrado hasta ahora, he observado siempre que el autor procede durante algún tiempo según la manera ordinaria de razonar (...) pero de repente me sorprende encontrar que en lugar de los procedimientos usuales es y no es, no hay proposición que no esté relacionada con un debe o no debe. Se trata de un cambio imperceptible, pero de consecuencias extremas. Pues como este debe o no debe expresa una nueva afirmación o relación, es necesario que sea notado y explicado, y, que al mismo tiempo, se dé una razón para lo que parece del todo inconcebible, a saber, como puede ser esta relación una deducción a partir de las otras» (Hume, Tratado acerca de la naturaleza humana. Libro III, parte I, sección I).

Desde el punto de vista lógico, todos los tratadistas reconocen que es posible derivar una norma (debe) de una afirmación factual (es). Deducir quiere decir etimológicamente 'sacar de'; y en la conclusión de un argumento deductivo no puede haber nada que no se hallare previamente en las premisas. Por esta razón si las premisas expresan relaciones fáticas, no hay modo de concluir proposiciones normativas. Asimismo, tampoco puede apelarse a la inducción, como mantiene el naturalismo clásico, pues, afirmar que debe hacerse ' $\mathrm{X}$ ' porque produce las consecuencias ' $\mathrm{Y}$ ' supone incurrir en la falacia naturalista del argumento de la pregunta abierta, es decir, siempre cabe preguntar si deben elegirse las consecuencias ' $\mathrm{Y}$ '.

El salto lógico entre es y debe existe (Radnitzky, 1980 y 1984; Hudson, 1974; Hudson (ed.), 1983; Muguerza, 1970; Touriñán, 1983, 1984, 1987 y 1987a; Ferrater, 1979a).

Como dice Popper (1967, pp. 94-97) la decisión de luchar contra la esclavitud, por ejemplo, no depende del hecho de que todos los hombres nazcan libres e iguales y de que nadie nazca encadenado. Aun cuando todos naciesen libres, podría suceder que algunos hombres intentasen encadenar a otros o que llegasen a creer, incluso, que es su 
obligación ponerles cadenas. Precisamente por eso puede afirmarse que ante un hecho cualquiera podemos adoptar diversas decisiones como, por ejemplo, alterarlo, protegerlo de quienes quieren modificarlo, abstenernos de intervenir, etc.

Por las razones anteriores hechos y decisiones no se confunden. La deliberación y la formulación de una decisión son hechos, pero lo que se ha decidido que debe hacerse no es un hecho.

Es sabido, que este planteamiento no necesita revisión. Entre hechos y decisiones morales hay un salto lógico. Pero, al mismo tiempo, mantenemos que necesita suplementación porque, como es sabido, acontecimientos intencionales y acontecimientos morales no se identifican necesariamente. Frente a este planteamiento deben tenerse en cuenta los siguientes argumentos: (Touriñán, 1987 y 1987a):

a) Junto con el rigor sintáctico debe reconocerse que, a nivel semántico, las significaciones de nuestros enunciados declarativos están afectadas por valoraciones y nuestros valores están apoyados en el significado que damos a los enunciados declarativos. Como hemos visto ya, hay un carácter axiológico en los hechos. Justamente por eso, cuando afirmamos que un trabajo tiene valor científico, estamos afirmando que ese trabajo cumple todo aquello que cuidadosamente hemos podido significar como científico.

b) En esta misma línea, dice Bunge que hemos caído en una trampa del lenguaje al considerar que el carácter orientador de la acción viene por frases que contienen el término debe.

Por una parte, existen comunidades primitivas que no disponen del término debe y orientan su acción por medio de condicionales de la forma 'si haces $\mathrm{X}$ ' te ocurrirá ' $\mathrm{Y}$ '.

Por otra parte, la diferencia entre 'no debes hacer $\mathrm{X}$ ' y 'si haces $\mathrm{X}$ te ocurrirá $\mathrm{Y}$ ' es primordialmente lógica, no pragmática. Únicamente, si al 'debes’ le atribuimos carácter absoluto e incondicional, la diferencia es de otro tipo, pero ello equivaldría irracionalmente a afirmar que esta norma tiene vigencia cualesquiera que sean las necesidades y circunstancias del sujeto que la elige:

«En cuanto advertimos que en el nivel pragmático se disuelven las barreras entre lo fáctico y lo normativo, empezamos a sospechar que el lenguaje ha estado pensando por nosotros (...). Un análisis incompleto - puramente sintáctico- nos ha hecho olvidar que una expresión puede poseer un contenido o efecto orientadores de la acción sin que en ella aparezcan términos ostensiblemente normativos» (Bunge, 1976, p. 18).

c) Una vez que nos damos cuenta que la relación sintáctica no anula la relación semántica y pragmática, la ciencia orienta la acción de manera inequívoca. Los enunciados nomológicos (no hay máquinas de movimiento continuo) justifican enunciados normativos tales como 'no intentarás construir el móvil perpetuo' (Bunge, 1976, p. 22). La propia ciencia sería incapaz de progresar si, ante la diversidad de aparatos técnicos y de teorías de un ámbito de conocimiento, no pudiese establecer normas frente a ellos que orientasen la acción del investigador (Bunge, 1976, p. 24).

Adviértase, además, que estas normas son y se hacen dentro del propio ámbito de conocimiento que la ciencia ha reservado para desarrollar su actividad. Son normas que nacen del proceso. No me dice la ciencia si yo debo pasear o hacer ciencia. Pero dentro del ámbito científico elegido para trabajar -la economía, la biología, la medicina, etc.es la propia ciencia la que dicta normas de orientación de la acción. 
d) Como dice Ladriere el paso de una proposición científica nomológica, a un enunciado pragmático, orientador de la acción en ese ámbito no constituye en modo alguno una inferencia lógica, representa un salto a nivel sintáctico, pero es un paso inevitable del 'es' al 'debe' en la consideración pragmática porque son actos engendrados por esas proposiciones:

"La no realización de las operaciones prescritas implica inevitablemente el no funcionamiento y hasta posiblemente la destrucción del sistema (en este caso, la ciencia). Esta formulación es la presentación en forma negativa, de una prescripción positiva que sería: si se quiere hacer funcionar correctamente tal sistema, estas son las instrucciones (...) lo que fundamenta la relación de consecuencia es el conocimiento que se tiene de las condiciones del funcionamiento del sistema en cuestión» (Ladriere, 1977, p. 108. La negrita es nuestra).

En efecto, fundándose en el conocimiento del funcionamiento del sistema que trabaja (historia, química, medicina, o cualquiera otra de las disciplinas científicas), el carácter axiológico de los hechos legitima al científico para no aceptar sin más cualquier tipo de objetivo que la sociedad pudiera proponerle como punto de partida para la elaboración de su teoría, porque, como ya sabemos, el propio marco teórico restringe el margen de posiciones de valor que justificadamente puedan adoptarse. Existe, por tanto, una normatividad intrínseca en la ciencia.

"Ya no es posible hoy en día considerar la ciencia como un simple instrumento exterior en relación a los fines propuestos. Ya no es dable distinguir entre los medios y los fines y, tanto que nos guste o no, nuestro destino y el de nuestra razón están consustanciados con el desarrollo de la ciencia que ya no puede ser más pensado en función del solo saber, sino en su responsabilidad» (Spaey, et al., 1970, p. 51).

El científico no tiene que aceptar cualquier tipo de condiciones y objetivos como científicos para elaborar sus teorías, porque existen objetivos que pueden descartarse con fundamento en el conocimiento del funcionamiento del sistema científico en que trabaja. Si la teoría sustantiva de la educación prueba que en las conductas programadas la conducta a realizar por el alumno esta lógicamente implicada con la función a la que se vincula, no queda legitimado pedagógicamente, y, por tanto, no se debe aceptar como objetivo de investigación, construir una teoría en circunstancias restringidas cuya utilización destruye o desprecia esa condición.

\subsection{El fundamento de la decisión técnica}

El ámbito de la decisión técnica se restringe a la elaboración de reglas y normas que se justifican desde el propio proceso de intervención (Touriñán, 1987 y 1987a; Rodríguez Martínez, 1989).

La investigación de la decisión técnica defiende la fundamentación de la elección en el conocimiento que se tiene del propio sistema. Es una orientación de la acción - de fines y medios- derivados directamente de la propia actividad elegida previamente (Bunge, 1976, p. 40). El objetivo directo de la acción supone compromiso moral -hacer ciencia- pero lo objetivos subsidiarios -qué se hace, cómo y qué voy a descubrir- son 
invenciones conceptuales, valoraciones y elecciones técnicas acerca de y sobre los datos de competencia exclusiva del científico (García Carrasco, 1985; Castillejo, 1985).

La elección técnica no es elección de medios para fines dados. Nos pueden proponer fines, pero es competencia del científico decir qué objetivos pueden fundarse como objetivos del ámbito. La elección técnica es elección de fines y medios subsidiarios que están lógicamente implicados en la tarea o lo que es lo mismo, elección de fines y medios subsidiarios con fundamento en el conocimiento de la actividad a realizar.

De acuerdo con nuestra exposición el esquema de elección técnica podría expresarse así:

$\mathrm{T}(=\mathrm{C} \rightarrow \mathrm{A})$

A es el objetivo a conseguir, y está legitimado por el marco teórico.

Constrúyase C.

Este esquema es el de la elección técnica, no sólo porque es una elección de un ámbito determinado de necesidades, sino también porque el criterio de decisión se funda estrictamente en el conocimiento del funcionamiento del ámbito en el que se actúa.

$\mathrm{Si}$ tomamos como ejemplo una expectativa social (por ejemplo el bilingüismo) el proceso que se da es el siguiente. Previo a la acción, el profesional asume el compromiso moral de educar -en lugar de hacer otra cosa- y de hacer bien su tarea. A partir de ahí, la expectativa (el bilingüismo) debe justificarse social y moralmente para la sociedad. Posteriormente, la expectativa se convierte en meta por decisión, entre otras cosas, si tiene valor educativo -que es asunto a resolver con el conocimiento de la educación-. Si se convierte en meta de la educación esa expectativa, desde el conocimiento de la educación se generarán reglas de intervención para hacer efectiva la meta (sujetos bilingües). Así las cosas, una vez que se acepta moralmente a una expectativa social, el conocimiento de la educación capacita al profesional para juzgar la valiosidad educativa de la expectativa, para participar en la decisión de adoptar esa expectativa como meta educativa y para desarrollar programas de intervención pedagógica, ajustados a hechos y decisiones pedagógicas, que hagan efectiva la meta.

Cabe la posibilidad ciertamente, de que un determinado gobierno pretenda que todas sus opciones se dirijan al sistema educación como fines de la educación, aunque no sean compatibles con el conocimiento de la educación. Cuando se fuerza al profesional a que trabaje para lograr un cambio que el propio conocimiento de la educación no confirma como valioso nos encontramos con un problema práxico cuya solución excede la competencia científica.

En estas situaciones, o existen oportunidades para que el profesional no tenga que actuar en contra de su código científico, o nos encontramos en un sistema político de privación real de libertades, o se convence al profesional de que no tiene competencia alguna respecto de la índole pedagógica de las metas a conseguir. Con todo, debe quedar bien claro que cualquiera de estas situaciones apuntan a la presencia o ausencia de oportunidades para ejercer la competencia profesional, pero no invalidan el rigor lógico de la competencia profesional, en las finalidades educativas y pedagógicas. En cualquier caso, lo que parece conveniente es que el carácter participativo de la toma de decisiones, respecto de las finalidades de la educación, no anule en modo alguno la valiosidad educativa de lo que se decide como fin, ni la condición de experto en el conocimiento de la 
educación para el profesional de la educación (Estler, 1988, pp. 305-320; Mitchell, 1988, pp. 453-466; Touriñán, 1987, pp. 178-181).

\subsection{El límite de la decisión técnica}

Si no soslayamos la dimensión de la decisión técnica, sigue siendo verdad que la ciencia no es suficiente para resolver los conflictos morales, pues hay que dar un salto lógico para resolverlos. Pero también es verdad que el propio proceso de intervención genera sus propias cuestiones acerca de sus metas que pueden ser resueltas desde el marco de la racionalidad científica.

Desde esta perspectiva decisiones morales y decisiones pedagógicas, no se confunden, porque ni los problemas morales se resuelven con el conocimiento pedagógico, ni los problemas pedagógicos se resuelven con el conocimiento moral.

Esta afirmación, que en principio puede parecer precipitada, se hace con la intención de clarificar el lenguaje y de evitar la neutralización de diferencias que una terminología menos precisa produciría entre conductas intencionales y morales. La distinción clásica entre acontecimientos morales, no morales e inmorales, puede retomarse a nuestro favor y afirmar lógicamente que toda conducta propositiva moral es a su vez intencional, pero no es cierta la conversa, lo cual coloca a la educación en una situación distintiva.

A favor de nuestra tesis hemos de esgrimir también la clásica distinción entre fines del objeto y fines del sujeto. La identificación de ambos fines, como dice magistralmente el profesor González Álvarez:

«no prueba nada porque confunde cosas que deben ser distinguidas y da por resueltas numerosas aserciones cuestionables y hasta falsas (...). Es cierto que la ética se ocupa de los fines; pero entiéndase bien, de los fines de su sujeto, no de los fines de los objetos que pertenecen a otras ciencias. La ética se ocupa del fin de los actos humanos, y, para mejor comprensión, del fin del hombre, de quien los actos que estudia son (...). La educación es en el hombre; pero no por eso se identifica su fin con el fin del hombre. Ante confusión semejante-demasiado frecuente por desgracia-anticipamos aquí que la educación es para el hombre (...). Sin embargo la educación no es el hombre (...). Como la ética se ocupa del ente moral (...) y la educación no se sitúa en una realidad de este tipo, la disciplina que trae de la educación no podrá quedar absorbida en la filosofía moral» (González Álvarez, 1977, p. 19).

Llegados a este punto del discurso, identificar sin más conductas intencionales y conductas morales en educación, sólo puede hacerse afirmando una de las dos siguientes cosas que no pueden aceptarse por más tiempo sin crítica: o bien se dice que problema moral y problema educativo son la misma cosa, o bien se dice que decisiones morales y decisiones de educación son la misma cosa. Ambas posiciones son refutables:

a) Problemas morales y problemas educativos no se confunden, porque no todo problema educativo se resuelve con el conocimiento moral. Si todo problema educativo es problema moral, se sigue que lo moralmente probado está de manera automática probado pedagógicamente. Frente a esta afirmación tenemos la experiencia de determinadas respuestas morales correctas que no pueden convertirse en metas educativas, porque se sabe que no pueden ser aprendidas por los educandos, mientras no superen un determinado nivel de desarrollo. 
Es obvio que en cuestiones morales, lo que no está vindicado moralmente, no se convierte con legitimidad en objeto o instrumento de la intervención pedagógica, por la misma razón que, en cuestiones históricas, no se convierte en meta de la educación lo que no esté probado históricamente. Asimismo, y para la educación, toda expectativa social tiene que estar moralmente justificada. Todo esto es condición para entrar en lo que podríamos llamar «candidato a meta de la educación». Pero, para que algo se convierta en meta de educación, como ya sabemos, además de la fundamentación propia de su ámbito, ha de poseer valor educativo -que es competencia propia del conocimiento de la educación. Posteriormente se convierte en meta, si se decide como tal frente a otras alternativas de valor educativo.

Como dice el profesor Escámez el patrón educacional tiene unos componentes espacio-temporales que permiten definir cuales de esas metas morales son objetivos legítimos en educación para un determinado nivel de desarrollo (Escámez, 1986, pp. 32-37).

b) Decisiones morales y decisiones de educación, tampoco se identifican. Desde el punto de vista de la investigación de la intervención existe la decisión técnica. El ámbito de la decisión técnica se restringe a la elaboración de reglas y normas que se justifican desde el propio proceso de intervención (Touriñán, 1987, pp. 156, 164).

El objetivo previo a la acción es el compromiso moral de elegir la tarea propia y hacerla bien; pero las cuestiones propias de la tarea elegida (en nuestro caso, educación) -qué se hace, cómo y qué voy a descubrir-son invenciones conceptuales, valoraciones y elecciones técnicas acerca de y sobre los datos de competencia propia del conocimiento de la educación.

En nuestra opinión, existe, en efecto, un ámbito de la educación que se identifica con el desarrollo de la dimensión moral. Desarrollar la dimensión moral es educar la decisión del hombre respecto de su propia vida y de las justificaciones de las opciones de vida. Pero incluso en esta dimensión ha de reconocerse que el conocimiento moral es un conocimiento especializado, distinto del de la educación, que se utiliza en educación para el desarrollo de destrezas morales y que no anula el carácter científico-tecnológico de la investigación pedagógica de fines y medios implicados en el proceso de la educación de la moralidad.

Evidentemente, a través de la educación se desarrolla la moralidad; pero en la actividad educativa hay que tomar múltiples decisiones de tipo técnico. En todas ellas el profesional tiene un compromiso ético previo, hacer bien su tarea, pero eso quiere decir dominar el conocimiento científico-tecnológico de la educación.

Si no confundimos conocimiento de áreas culturales, conocimientos morales y conocimiento de la educación, se entiende que es posible desarrollar para la función pedagógica un conocimiento específico que es estrictamente un conocimiento de hechos y decisiones técnicas, de tal manera que pueda afirmarse con sentido, no sólo que cualquier medio no queda legitimado pedagógicamente para alcanzar una meta social deseable, sino también que cualquier meta social deseable no se convierte automáticamente en una meta pedagógica legitimada.

\section{ELECCIÓN TÉCNICA Y ELECCIÓN MORAL}

La existencia de elecciones técnicas en la ciencia, como elección de fines y medios fundada en el conocimiento del funcionamiento de la actividad a realizar, hace que elec- 
ciones que hasta el momento se consideraban genuinas elecciones morales (como es el caso de la elección del médico entre decir una verdad y salvar la vida de un paciente, cuando éste está en estado crítico y la verdad que le comunica una noticia desagradable va a provocar una reacción negativa en su estado de salud, o como es el caso del profesor que tiene que elegir entre respetar la condición de agente en el educando o inculcarle la fidelidad al código moral específico de un determinado grupo) hayan pasado a tener un fundamento de tipo científico, permite afirmar que las elecciones técnicas crean valores morales. En la ciencia, no sólo hay valores de su ámbito sino también normas técnicas que crean orientaciones de la acción. Técnicamente hablando el médico no debe decir la verdad, si con ello destruye el sistema de curación. Técnicamente hablando el profesional de la educación no debe inculcar fidelidad al código de un grupo, si para ello anula toda posibilidad en el educando de analizar críticamente los fundamentos del código, porque eso va en contra de su condición de agente y puede descartarse por tanto, con fundamento de elección técnica. En cualquier caso esta peculiar situación nos obliga a reconocer que el contenido de la ciencia no está libre intrínsecamente de esas valoraciones.

A nosotros como personas se nos plantean elecciones de tipo técnico de diverso grado de libertad, una vez que hemos decidido ser profesionales de la educación.

a) Hay situaciones con grado de libertad del deber simple, son situaciones en las que con fundamento en el conocimiento del funcionamiento del sistema, ponemos en marcha las instrucciones que nos permiten lograr un aprendizaje en el alumno.

b) Hay situaciones con grado de libertad del deber más urgente, son situaciones en las que con fundamento en el conocimiento del funcionamiento del sistema, decido aquellos objetivos que la propia situación reclama o entre dos objetivos educativos que son incompatibles en cuanto al momento de realización, si bien ninguno de ellos anula radicalmente la posibilidad de elegir el otro en un momento posterior.

c) Hay situaciones con grado de libertad del deber fundamental, son situaciones en las que con fundamento en el conocimiento del funcionamiento del sistema, decidimos acerca de aquello que beneficia al sistema. Es el caso en que descartamos que no se legitiman pedagógicamente. Es el caso en que decidimos poner en marcha un objetivo cuya ausencia anula radicalmente la posibilidad de elección de otros posteriormente (elección de destrezas básicas, por ejemplo). Es el caso en que elegimos aquello que favorece al sistema (elección de la adquisición de una destreza intelectual con preferencia a la adquisición de un contenido cultural de un área de conocimientos). Es el caso en que decidimos no inculcar fidelidad a un código, si para ello tenemos que anular la posibilidad de respuesta crítica de los alumnos a los principios que fundamenta el código.

En todos estos casos el paso del 'es' al 'debe' está fundado en el conocimiento del funcionamiento del sistema. Son elecciones técnicas de objetivos y medios subsidiarios.

Pero además, a nosotros se nos pueden plantear, con esos diversos grados de libertad, elecciones morales genuinas, es decir, se nos van a plantear opciones para orientar nuestros personales objetivos de acción: ¿debo ir a la escuela hoy? ¿debo cumplir las promesas hechas? ¿debo respetar la vida de mi enemigo? En todos estos casos, la elección que orienta nuestra vida no tiene un objetivo, sino la simple y complicada afirmación de que el valor de cada una de esas cosas se elige como meta última, aquí y ahora, con carácter de opción fundamental y sin un objetivo previo elegido. Cuando nos preguntamos si debemos ir a la escuela hoy, no estamos haciendo una pregunta de elección 
técnica; si elegimos educar, debemos ir al lugar en que lo hacemos. Nos estamos planteando un problema moral: ¿existe un deber más fundamental hoy para nosotros que ir a la escuela? Por ejemplo ¿debemos ir a la escuela, o debemos atender a nuestra madre enferma? Ambas opciones son igualmente urgentes; las dos son requeridas por la situación. Pero tenemos que decidir cual es la más fundamental.

Las elecciones de la ciencia son técnicas porque se hacen a partir de un objetivo previamente elegido. Es decir, un médico decide que no debe decir la verdad porque eso es condición necesaria para curar a un paciente (que es su ámbito de actividad), pero la ciencia no puede decirnos lo que es bueno moralmente hablando. Preguntas tales como debemos ir a la escuela hoy, debemos elegir la educación, no se responden desde la ciencia. Desde la ciencia sabemos qué cosas son de valor educativo, cómo lograrlas, y qué debemos hacer una vez que hemos decidido educar, pero la ciencia no nos da la respuesta al problema de si debemos educar o hacer otra cosa, porque esa respuesta exige una comparación entre valores de carácter relativo a las necesidades de cada persona para orientar su propia vida (Ferrater, 1979a, pp. 119-155). No se trata de afirmar que, cuando elegimos uno de esos valores, los demás no sean valiosos. Valor y elección son distintos. Se trata más bien de resolver la cuestión de si hay un deber más fundamental que el otro aquí y ahora. Cuando el médico dice que debe mentir o que no debe decir la verdad a su paciente, lo hace con fundamento de elección técnica. No es que sea valioso mentir, sino que hay un deber más fundamental que decir la verdad, porque si lo que ha decidido es curar, esa relegación se impone como condición necesaria. Pero cuando estamos centrados en el objetivo prioritario de la acción no está claro cual es el patrón por el cual decido. Si decimos que debemos sacrificar nuestra vida para mantener un secreto, estamos haciendo un juicio moral que supone comparación entre valores: el valor de la vida y el valor de la promesa. Si decimos que debemos sacrificar nuestra vida para mantener un secreto cuyo desvelamiento implicaría desastres para el que nos lo ha confiado, elegimos por las consecuencias. No hay duplicado de experiencia porque el argumento inductivo, como hemos dicho al estudiar la decisión pedagógica, deja siempre la posibilidad de preguntarse si debemos elegir las consecuencias ' $y$ ' que son las que se producen al elegir nuestra vida a pesar de los desastres que le ocasione al que me ha confiado el secreto. Tampoco nos basta la elección técnica con su paso del 'es' al 'debe' porque sólo sirve para fundamentar elecciones dentro del sistema, es decir, una vez que uno ha elegido ya respetar la promesa.

Hoy estamos en condiciones de afirmar que la ciencia no es suficiente para resolver una opción moral, esta opción es personal y la ciencia no la realiza por nosotros. Ahora bien, que no sea suficiente no quiere decir que no sea necesaria. Del hecho de que una cosa exista no se sigue que sea bueno (moralmente) que exista, pero el que sea bueno (moralmente) que exista depende de un claro conocimiento de lo que es (Kolhberg, 1971; Toulmin, 1979 y 1980; Turiel, 1984; Asch, 1968; Bunge 1976, pp. 76-77). En este mismo sentido se expresa Brandt cuando afirma que la argumentación racional no está fuera de las elecciones morales: las actitudes, las reglas lógicas de razonamiento y los principios apoyados en el conocimiento son componentes de la elección moral (Brandt, 1982, pp. 288-297).

Toda elección moral se hace en base al mejor conocimiento teórico de las situaciones en las que debo elegir (Feinberg, 1979; Foot, 1974; Peters, 1979 y 1974). Si nosotros decimos que debemos destruir las razas inferiores, enuncio una proposición moral que es 
incorrecta porque carece de fundamento teórico, ya que está demostrado que no existen razas inferiores. En la misma medida que nuestro interés es descubrir y mantener la verdad, diremos que ese enunciado moral es objetivamente inferior al enunciado 'no harás discriminaciones raciales' (Bunge, 1976, p. 55).

Es necesaria la ciencia para resolver los conflictos morales. No es suficiente, porque la elección moral se hace con respecto a las necesidades que nosotros tengamos en cada momento, y decidir cual de nuestras necesidades es más fundamental supone una referencia a nuestros sentimientos, actitudes e intereses, que nosotros podremos corregir y variar, si descubrimos que su fundamento cognoscitivo no es correcto, pero que no podemos tenerlos en el momento de adoptar la decisión.

Así las cosas, la neutralidad moral intrínseca nos parece una afirmación exagerada y poco ajustada a la realidad de la acción. Es cierto que la ciencia no elige moralmente por nosotros, pero un componente básico de la elección moral depende de la ciencia. Que la ciencia no haga juicios morales genuinos por nosotros, no quiere decir que nosotros los podamos hacer correctamente sin la ciencia, y si esto es así, hay competencia de la ciencia en juicios morales genuinos, al menos para decir cuándo una norma moral tiene fundamento teórico (Dunkel, 1972; Thomas, 1972).

\section{DECISIONES TÉCNICAS Y DECISIONES DE POLÍTICA EDUCATIVA}

La decisión es un acto por el que se responde, de acuerdo con las oportunidades, a una realidad interna y externa que modifica la premiosidad de las necesidades (Touriñán 1989a; Rodríguez, 1989). En general, la decisión identifica un curso de acción, por eso se dice que la teoría de la decisión trata el problema de la elección entre dos o más cursos de acción, que son decisiones posibles, en orden a encontrar el óptimo, según las preferencias del decisor. En este sentido, tomar una decisión es elegir, entre varias alternativas posibles, una de ellas. Precisamente por eso puede decirse que tomar una decisión es realizar un juicio sobre esas alternativas y elegir la que se considere mejor. $\mathrm{Y}$ esto, en el fondo, no es más que afirmar un valor que se elige (García Hoz y Medina, 1986; Gómez Bezares, 1986; Touriñán, 1989a).

Otro modo de acercarse a la decisión es considerarla como proceso. En este caso la decisión es «el proceso mediante el cual se llega a la elección de un curso de acción entre un conjunto de cursos alternativos» (Gómez Dacal, 1981, p. 14). Entender de este modo la decisión implica atribuir al proceso «un dinamismo racional continuo, mediante el cual, partiendo de ciertos datos y efectuando un análisis y una valoración sobre la conveniencia y sobre las consecuencias de las soluciones alternativas posibles, respecto de un determinado objetivo, se llega a efectuar la elección final» (Jiménez, 1986, p. 134).

Las decisiones que se toman en la Política, en general, y en la Política Educativa, en particular, se centran, fundamentalmente, en establecer las prioridades y estrategias de logro que el poder político, en su función de servicio, cree necesarias para el buen funcionamiento del Estado o del Sistema Educativo (en el caso de la Política Educativa) y, en última instancia, para la mejora de la Sociedad.

El objetivo general de la decisión en política educativa es determinar cuales son las necesidades que demanda la sociedad en materia educativa y como se pueden satisfacer, para establecer, de acuerdo con los presupuestos económicos, cuales son las prioridades 
educativas que se pueden alcanzar y cuales, por consiguiente, deben ser financiadas. En este sentido las decisiones de la política educativa tienden a cubrir la demanda social o las necesidades en materia educativa de modo diverso, según las concretas circunstancias de cada período de gobierno.

La elección de los fines y la asunción de las estrategias de logro a nivel político constituyen lo que denominamos decisiones políticas, es decir, aquellas decisiones que adopta el poder político para satisfacer, tanto las demandas sociales como las metas de logro que aquel cree prioritarias con respecto a otras finalidades o estrategias en esa circunstancia concreta de gobierno. Estas decisiones se basan en variables no sólo del ámbito sobre el que se ejerce la acción de gobierno -salud, vivienda, agricultura, etc.-, sino también en otras variables de otros ámbitos de la realidad, como el económico, el ideológico, el socio-cultural, etc. (Rodríguez Martínez, 1989).

En líneas generales, las decisiones políticas son aquellas que adopta el poder político como prioritarias para el desarrollo de un ámbito, teniendo en cuenta las demandas y las necesidades sociales del mismo, así como las interpretaciones que sobre estas demandas y necesidades sociales se hacen desde los distintos ámbitos de la realidad. El esquema de la decisión política podría ser representado de la siguiente forma:

$$
\begin{aligned}
& P=\left(\mathrm{X}_{1} \vee \mathrm{Y}_{1} \vee \mathrm{Z}_{1} \rightarrow \mathrm{A}\right) \mathrm{V}_{\mathrm{s}}\left(\mathrm{X}_{2} \vee \mathrm{Y}_{2} \vee \mathrm{Z}_{2} \rightarrow \mathrm{B}\right) \mathrm{V}_{\mathrm{s}}\left(\mathrm{X}_{3} \vee \mathrm{Y}_{3} \vee \mathrm{Z}_{3} \rightarrow \mathrm{C}\right) \\
& \text { Donde: }
\end{aligned}
$$

$A, B, C$, son expectativas sociales sobre ámbitos específicos (sanidad, educación, vivienda, etc.), que son objetivos a conseguir y que están legitimadas por el conocimiento propio de cada ámbito y reconocidas socialmente como necesidad de ese ámbito determinado.

$X ; Y ; Z$ son distintas alternativas para alcanzar $A, B, C$, justificadas con el conocimiento propio de ese ámbito.

$P$ es la decisión política que fija la prioridad de una expectativa sobre otra desde el punto de vista político basándose en variables socio-culturales, económicas e ideológicas, básicamente, y asume una expectativa y un modo de lograrla.

Si trasladamos el esquema de la decisión política a la decisión de política educativa, nos encontramos con que:

$$
P_{E}=\left(\mathrm{X}_{1} \mathrm{v} \mathrm{Y}_{1} \mathrm{v} \mathrm{Z}_{1} \rightarrow \mathrm{A}_{\mathrm{E}}\right) \mathrm{V}_{\mathrm{s}}\left(\mathrm{X}_{2} \mathrm{v} \mathrm{Y}_{2} \mathrm{v} \mathrm{Z}_{2} \rightarrow \mathrm{B}_{\mathrm{E}}\right) \mathrm{V}_{\mathrm{s}}\left(\mathrm{X}_{3} \mathrm{v} \mathrm{Y}_{3} \mathrm{v} \mathrm{Y}_{3} \rightarrow \mathrm{C}_{\mathrm{E}}\right)
$$

Donde:

$A_{E}, B_{E}, C_{E}$, son metas educativas, reconocidas socialmente y legitimadas por el conocimiento del ámbito 'educación'.

$X ; Y ; Z$ son alternativas para alcanzar las metas. Estas alternativas se establecen por medio del conocimiento de la educación (experiencial, teoría práctica o tecnología específica).

$P_{E}$ es la decisión de política educativa que fija la prioridad de una de esas metas con su alternativa de acción bajo variables de oportunidad, eficacia, coherencia socio-cultural, pertinencia ideológica y posibilidad económica, básicamente.

Con la decisión de política educativa, entramos, por tanto, en un ámbito de racionalidad que desborda el ámbito científico-tecnológico: la forma de conocimiento práxica, que se aplica con todos sus postulados a la decisión política que tiene su carácter distintivo frente a las decisiones técnicas y morales, como hemos visto. Puede afirmarse que la decisión técnica se identifica con reglas y normas derivadas del propio proceso, en función del conocimiento que se tiene del ámbito específico y a partir de la elección 
primaria de trabajar en ese ámbito. A su vez, la elección moral no es elección dentro de un ámbito, sino confrontación de ámbitos diversos respecto de la propia vida y proyecto personal; es la ordenación que hace el hombre de sus exigencias de acuerdo con las relaciones que se dan en la realidad en cada ámbito de su existencia. Por su parte, la elección política es, con propiedad, ordenación de metas y alternativas de acción para lograrlas, pero no respecto de la propia vida personal sino respecto del bien común vinculante en la sociedad.

El complejo científico-tecnológico se caracteriza en nuestros días por el cambio de consideración de la actividad que le es propia. "La acción adaptativa (a objetivos dados) es sustituida por la acción prospectiva que se propone de antemano los objetivos y ordena los medios disponibles (...) la ordenación se hace en función no de un desarrollo inevitable de los fenómenos, sino de un proyecto general que impone los objetivos, fija las prioridades, los criterios de elección, las normas de actuación» (Ladriere, 1977, p. 118. La negrita es nuestra). El conocimiento tecnológico, en tanto que intervención en los acontecimientos, afecta al objeto mismo investigado. Las decisiones técnicas en el conocimiento tecnológico afectan a los programas de investigación y al estado real del objeto intervenido.

Existe, además, un conocimiento práxico (político-práctico, para otros autores). Es el encargado de orientar la acción respecto de los objetivos directos de la acción en el orden común vinculante. Para este conocimiento no basta la racionalidad científico-tecnológica. Es necesaria pero no suficiente.

La teoría y la tecnología son en este sentido 'impráxicas' (no suficientes para resolver conflictos práxicos), pero no están desligadas de la vida 'práxica'. Algunos, a partir de aquí, sienten la tentación de vincular ciencistamente la moral a la ciencia, elevando a rango de verdad última la verdad científico-técnica (Quintanilla, 1981, pp. 111-114). Pero este modo de actuación implica que «la ciencia y la técnica adoptan el papel de una ideología (...//...) el progreso científico técnico, sometido a control se convierte él mismo en fundamento de legitimación de toda opción moral (...//...) el núcleo ideológico de esta conciencia es la eliminación de la diferencia entre práctica y técnica (...//...) la autorresponsabilidad absoluta se funda en perspectivas teóricas absolutas» (Habermas, 1984, pp. 86, 96, 99 y 165).

Consiguientemente, tiene sentido afirmar que el investigador ni dicta los fines de la política (no es suficiente la racionalidad científica), ni está al margen de esas orientaciones del objetivo directo de esa acción (es necesaria la racionalidad científica), ni tiene que estar sometido a cualquier propuesta de objetivo subsidiario para su ámbito de trabajo, porque es suficiente la racionalidad científico-técnica para decidir fines y medios subsidiarios. Pero, por la misma razón, el político que elige moralmente hacer bien su trabajo, no queda sometido sin más a los dictados técnicos.

Nos parece un error subsumir la racionalidad práxica en la racionalidad científicotecnológica. No comprender ese error es abrir la legitimación de la destrucción de pueblos enteros por el simple hecho de observar los efectos. Al científico se le plantean problemas de elección técnica; con fundamento de elección técnica es perfectamente legítimo que un médico decida mentir a su paciente para salvarle la vida, que un biólogo descubra los efectos de una plaga y sepa controlarla, o que un pedagogo no acepte como objetivo educativo la destrucción de la condición de agente del educando. Pero al biólogo, al médico, al pedagogo se les plantean problemas de acciones morales genuinas que no pueden resolver con su competencia técnica sino humanamente con racionalidad práxica: ¿es lícito que se use el descubrimiento biológico acerca de los efectos de una plaga 
en contra de los hombres?, ¿es lícito que se utilicen las personas como conejos de indias para experimentos clínicos?, ¿es lícito mermar la eficacia de la educación escatimando las partidas del presupuesto? Estas cuestiones son ejemplos de las situaciones en las que la elección moral está presente (Tisseltus y Nilsson, 1971; Koestler et al. 1969; Polanyi, 1964; Scheuerl, 1984). Pero, además, al biólogo, al médico o a las personas, se les pueden plantear problemas políticos, si ese es su campo de trabajo y estos no se resuelven desde la ciencia o desde la moral.

Así las cosas, la cuestión fundamental en el debate «ciencia-moral-política» no es el litigio acerca de la neutralidad de la investigación, sino la pretensión de ciencismo, es decir, el intento atractivo de ir más allá de la decisión técnica -propia de la indagación científica- sólo con la decisión técnica o el paternalismo derivado de una identificación de las decisiones técnicas y de las decisiones políticas con las decisiones morales.

En nuestra opinión, puede afirmarse que el conocimiento científico de la educación está presente en la identificación de las necesidades y en la elaboración de modos de solucionar necesidades. Pero la decisión es política, porque no se puede escoger la solución sólo con el conocimiento técnico de cada ámbito (Pedagogía, Medicina, Arquitectura, Ética, Moral, etc.) sino que se escoge teniendo en cuenta otras variables propias de lo político para establecer la prioridad como pueden ser en nuestro caso, con respecto a la educación, el económico, el ideológico, el social, el cultural, etc. en cada circunstancia concreta.

Siendo esto así, la decisión de política educativa, por su propia estructura, no puede contradecir el conocimiento del ámbito sobre el que se decide, porque es parte integrante del proceso de toma de decisión; pero puede soslayarlo, restándole oportunidad. Este es el caso de una política educativa que justifica la merma de inversión, porque se ha prestado más atención a la sanidad que a la educación ese año, y, consecuentemente, destina el presupuesto en buena parte a aquella necesidad, pues, con criterios políticos adecuados, se conviene que aquella es la acción decidida. De este modo no hay contradicción con el conocimiento de la educación; pero se acepta implícitamente que la tarea educativa no será la prioritaria en esa ocasión a efectos de inversión.

El postulado básico de la decisión política es que ésta es correcta siempre que no se contradiga lo demostrado por el conocimiento propio del ámbito de la realidad sobre el que se decide (en nuestro caso, la educación). Se entiende, por tanto, que la decisión política parta casi siempre de alternativas y soluciones que le presentan los técnicos de cada ámbito (informes de expertos). En este sentido, el político no tiene que decidirse necesariamente a favor de un determinado problema, pero en el problema que elija como prioritario, ha de adoptar la solución satisfactoria por el conocimiento técnico del ámbito al que pertenece el problema. Esto es así, porque en su decisión cuentan variables externas e internas al ámbito que se convertirá en prioritario. Estas alternativas o soluciones que presentan los técnicos o especialistas se conocen genéricamente como decisiones técnicas y se fundamentan en el conocimiento que se tiene del ámbito en el que se decide (en nuestro caso, el conocimiento de la educación).

\section{DECISIONES DE POLÍTICA EDUCATIVA Y FINALIDADES}

Antes de concluir este trabajo, quisiéramos llamar la atención sobre una de las virtualidades más peculiares de las decisiones de política educativa: por el hecho de cen- 
trarse en la oportunidad para priorizar y por el hecho de afectar a variables internas y externas al problema que se prioriza, en la decisión de política educativa, las finalidades no son estrictamente hablando criterios de decisión externos al propio sistema y tienen que ser consideradas como constantes aceptadas provisionalmente en los procesos de planificación.

Nos parece importante destacar esta tesis, porque su afirmación supone una conmoción en la validez del esquema «fin-medios».

En el esquema fin-medios, el fin designa aquel efecto o complejo de efectos que han de justificar la acción. El esquema fin-medios postula, en su idea fundamental, una relación entre valores, como dice Luhman:

«el establecimiento de los fines supone que el valor de los efectos que se tienen como fin, acierta a fundamentar la acción (.......) el concepto de fin y medio presupone una relación causal, pero no la describen en cuanto tal, sino que más bien expresan, al igual que el principio de transitividad, una relación axiológica entre los efectos del obrar (...). Este esquema (como sigue diciendo Luhman) es una inversión de la histórica y abandonada idea del fin como causa de los medios, pues no es que se diga que el fin causa los medios, sino que los medios son causa de un efecto pretendido» (Luhman, 1983, pp. 42-43).

Así las cosas en el esquema fin-medios, el fin es un efecto pretendido que, depende de valores preconcebidos y puede fijarse por tanto de antemano (Wheeler, 1976, p. 86).

La obra de Dewey Democracia y educación aborda el problema de los fines desde la crítica del esquema fin-medios. Dentro de una determinada actividad

«la distinción medio-fin es una distinción de conveniencia. Todo medio es un fin temporal hasta que lo hayamos alcanzado. Todo fin llega a ser un medio de llevar más allá a la actividad tan pronto como se ha alcanzado. Lo llamamos fin, cuando señala la dirección futura de la actividad a que estamos dedicados; medio, cuando indica la dirección presente. Todo divorcio entre el fin y los medios disminuye la significación de la actividad» (Dewey, 1971, p. 118).

La apelación a la experiencia que hace este texto obliga a aceptar la relatividad del esquema fin-medios. La caracterización de un factor como fin o como medio depende de la perspectiva temporal escogida. La relatividad del fin y de los medios es enteramente familiar al pensamiento moderno. No es posible por cuestión de espacio detenerse en el desarrollo que hace Luhman de esta tesis. Sin embargo, nos parece pertinente insistir en varias cuestiones que dificultan la firmeza del esquema medios-fines.

La primera cuestión es el postulado del orden preferencial transitivo. Cuando el fín es un efecto pretendido, su justificación se hace en términos de la valiosidad del efecto, lo que significa acudir necesariamente al postulado del orden preferencial transitivo. Este postulado mantiene que, si $A$-que es un valor-es preferible a $B$-que es otro valory $B$ es preferible a $C$, se sigue que $A$ es preferible a $C$. Es este postulado de transitividad el que se mantiene en el esquema medios-fines, porque, en última instancia, el valor del efecto que se tiene como fin, justifica la acción.

En principio, y frente a esta posición, debe recordarse que los valores no son inversiones más o menos intensas de un determinado valor previo y último, sino cualidades relacionales susceptibles de conocimiento. Precisamente por eso, cada valor vale en el ámbito del conocimiento en que es descubierto y creado, y, también por eso, la elección de un valor de un ámbito no sustituye al de otro. 
Por otra parte, los estudios de la lógica de la preferencia han permitido comprobar que el modelo de preferencia transitivo sólo es aplicable, tautológicamente, si el hombre se orienta transitivamente. D. J. White, $(1979$, p. 32) muestra que, en la compleja situación del obrar humano, mantener la transitividad no es realista, porque ello supone fijar las preferencias de la acción, sólo para mantener el principio, con independencia de las oportunidades y al margen de la influencia de las circunstancias en la premiosidad de las necesidades.

En este sentido, las teorías de mayor credibilidad en el campo de la organización, actualmente, defienden, no el postulado de la transitividad, sino el de los standars satisfactorios de decisión. J. G. March y H. A. Simon en su obra Teoría de la Organización, que lleva cinco ediciones en castellano, mantienen esta posición y afirman que los standars satisfactorios ocupan generalmente la decisión, porque la cuestión no es buscar en un pajar la aguja más puntiaguda, sino una aguja lo suficientemente puntiaguda para coser (March y Simon, 1981, p. 155).

La segunda cuestión que dificulta la firmeza del esquema fin-medios es una consecuencia del postulado del orden preferencial transitivo. Cuando se postula la transitividad, se está imponiendo la organización vertical de los fines y de los agentes encargados de cumplirlos. El fin de la cúpula de la organización se convierte en algo externo para los diversos niveles de ejecución del sistema y se reduce al mínimo la autonomía profesional en los niveles inferiores, pues los fines, ni se deciden en cada nivel, ni son orientadores, es decir, 'fines-previstos', sino 'fines fijados'. De manera concreta dice Dewey:

«El vicio de los fines externamente impuesto tiene sus raíces profundas. Los maestros los reciben de las autoridades superiores; estas autoridades los aceptan de lo que es corriente en la comunidad. Los maestros los imponen a los niños. Como primera consecuencia, la inteligencia del maestro no es libre; está reducida a recibir los fines dictados desde arriba. Con muy poca frecuencia el maestro se ve libre del dictado del inspector oficial, del texto de metodología (...). Esta desconfianza respecto a la experiencia del maestro se refleja entonces en la falta de confianza respecto de las respuestas de los alumnos»(Dewey, 1971, p. 21).

Las críticas a los sistemas de organización Tayloristas, que es la que corresponde al esquema vertical de decisión, son conocidas en el momento actual. Las críticas no son en este caso sinónimo de absoluto abandono del modelo, sino de conveniente transformación para lograr una mejor adecuación a las situaciones que plantean los sistemas de gestión. En nuestro campo, tanto las críticas tradicionales (Wheeler, 1976, p. 199), como las más recientes (Gimeno, 1988, pp. 167-175) coinciden en que el carácter externo de los fines hace que la planificación de largas cadenas de derivación desde los fines de la cúpula carezcan de efectividad, porque la diversidad de tareas de los agentes en cada nivel de la cadena genera criterios decisorios diferentes y provoca discontinuidad (Gimeno, 1988, pp. 168, 169 y 344). De manera muy especial el profesor García Carrasco insiste en la imposibilidad de reducir la complejidad de la acción a esquemas lineales y en la necesidad de adscribir el concepto de fin a sistemas con una dimensión plural y no excesivamente personal en la definición de los actores (García Carrasco, 1986, p. 132).

La tendencia apunta a sustituir los modelos verticales de decisión por modelos sistémicos en los que el cumplimiento de fines no se realiza mediante planificación de largas 
cadenas de derivación, sino primariamente a través de la formación de subsistemas. El supuesto básico es que puede desarrollarse una coordinación suficiente, aceptando que los subsistemas tienen su propia identidad, su propia organización de variables, de tal manera que pueden contemplar desde su propio nivel de decisión todos los fines lejanos o externos a manera de factores ambientales. De este modo, no es el fin el que se fracciona hasta resultar irreconocible en algunos niveles (Wheeler, 1976, pp. 37-40, 117-140 y 199; Gimeno, 1988, pp. 121-126), sino que cada nivel de intervención o subsistema -Administración central, Comunidades Autónomas, Centros escolares, profesor en el aula- tiene sus propios fines y contempla los correspondientes a los demás niveles a modo de variables ambientales que serán integradas según su compatibilidad con los criterios de toma de decisiones del subsistema (Luhman, 1983, p. 243-250).

La tendencia actual de la investigación apunta la comprensión de los fines desde esquemas sistémicos. Este tipo de esquemas, que en nuestro campo han sido introducidos por el profesor Sanvisens, tienen hoy en nuestro ámbito construcciones sistematizadas que permiten continuar el estudio de las cuestiones que en este apartado hemos planteado con objeto a avanzar en las decisiones de política educativa (Sanvisens, 1986, pp. 33-51; Castillejo, 1987, pp. 103-104; Castillejo y Colom, 1987; D'Hainaut, 1988).

\section{BIBLIOGRAFÍA}

AsCH, S. E. (1968). Psicología social. Universitaria, Buenos Aires.

BRANDT, R. B. (1982). Teoría ética. Alianza Universidad, Madrid.

BROUdY, H. S. (1977). «Types of knowledge and purpose of education». En R. C. ANDERSON et al. Schooling and the adquisition of knowledge (1-17). Laurence, Erlbaun Associates, Nueva Jersey.

Bunge, M. (1976). Ética y ciencia. Siglo XX. Buenos Aires.

- (1981). Epistemología. Ariel, Barcelona.

ByRNES y CHESTERTON (1987). Decisiones estratégicas. El Ateneo, Buenos Aires.

CAstillejo, J. L. (1985). «Acciones pedagógicas versus condicionamientos sociales y políticos». En J. L. CASTILlejo et al. Condicionamientos socio-políticos de la educación (151-168). CEAC, Barcelona.

- (1987). Pedagogía tecnológica. CEAC, Barcelona.

Castillejo, J. L. y Colom, A. J. (1987). Pedagogía Sistémica. CEAC, Barcelona.

CElorrio, R. (1993). «Propuestas de un modelo de evaluación de centros y programas». Revista de Ciencias de la Educación (153), 121-136.

CHAlmers, A. F. (1982). ¿Qué es esa cosa llamada ciencia? Una valoración de la naturaleza y el estatuto de la ciencia y sus métodos. Siglo XXI, México.

DEWEY, J. (1971). Democracia y educación. Losada, Buenos Aires.

D’HaINAUT, L. (1988). Los sistemas educativos: Su análisis y regulación. Narcea, Madrid.

DUNKEL, H. B. (1972). «Wanted: new paradigms and a normative base for research». En L. G. THOMAS (ed.). Philosophical redirection of educational research (77-93). Yearbook of the National Society for the Study of Education. $1^{a}$ parte. University of Chicago. 
ESCÁmEZ, J. (1986). «Los valores en la Pedagogía de la intervención». En J. L. CASTILLEJo et al. Conceptos y propuestas III (29-48). Nau Llibres, Valencia.

ESTLER, S. E. (1988). «Decision Making». En N. J. BoYAN (ed.). Handbook of research on educational administration. 305-320. Longman, Nueva York.

FEINBERG, W. (1979). «Ethics and objectivity. The efects of Darwinian revolution on educational reform». Educational Theory. 23, (4), 294-302.

FERRATER, J. (1979). Diccionario de filosofia. Alianza Editorial, Madrid.

- (1979a). De la materia a la razón. Alianza Universidad, Madrid.

FEYERABEND, P. (1981). Tratado contra el método. Tecnos, Madrid.

Foot, PH. (1974). Teorías sobre la ética. Fondo de Cultura Económica, México.

García Carrasco, J. (1985). «Ideología y discurso pedagógico». En J. L. Castillejo et al. Condicionamientos socio-políticos de la educación (38-74). CEAC, Barcelona.

- (1986). «Reflexiones sobre la intervención pedagógica a propósito de un estudio de T. Parsons». En la obra conjunta: Tecnología y Educación (127-154). CEAC, Barcelona.

García Hoz, V. y Medina Rubio, R. (1986). Organización y gobierno de los centros educativos. Rialp, Madrid.

GIMENO, J. (1988). El currículum. Una reflexión sobre la práctica. Morata, Madrid.

Gómez Bezares, F. (1986). «Decisión (teoría de la)». En G. Gómez Dacal (coord.): Administración educativa. Diccionario de Ciencias de la Educación (137-142). Anaya, Madrid.

GómEz DACAL, G. (1981). «La teoría general del sistema aplicada al centro escolar». Revista de Educación. 28, (266), 5-49.

GonzÁlez Álvarez, A. (1977). Filosofía de la Educación. Troquel, Buenos Aires.

Habermas, J. (1984). Ciencia y técnica como 'ideología'. Tecnos, Madrid.

HIRST, P. H. (1974). Knowledge and the curriculum. A collection of philosophical pappers. Routledge and Kegan Paul, Londres.

Hudson, W. D. (1974). Filosofia moral contemporánea. Alianza Universidad, Madrid.

- (ed.) (1983). The is ought question. A collection of pappers on the central problems in moral philosophy. The MacMillan Press, Londres.

JimÉnez Eguizábal, J. A. (1986). «Decisión». En G. Gómez DaCAl (Coord.). Administración educativa. Diccionario de Ciencias de la Educación (134-137). Anaya, Madrid.

KoERTGE, N. (1982). «Hacia una nueva teoría de la investigación científica». En G. RADNITZKY et al. Progreso y racionalidad en la ciencia (227-248). Alianza Universidad, Madrid.

KoESTLER, A. et al. (1969). Beyond reductionism. Radius Books, Nueva York.

KOLHBERG, L. (1971). «From is to ought. How to commit the naturalistic fallacy and get away with it in the study of moral development». En T. MISCHEL (ed.). Cognitive development and epistemology (151-284). Academic Press, Nueva York.

LADRIERE, J. (1977). El reto de la racionalidad. Sígueme, Salamanca.

LARSON, M. S. (1988). «El poder de los expertos: Ciencia y educación de masas como fundamento de una ideología». Revista de Educación (285), 191-215. 
Luhman, N. (1983). Fin y racionalidad en los sistemas. Sobre la función de los fines en los sistemas soiales. Editora Nacional, Madrid.

Macnamara, J. F. y Chicolm, G. B. (1988). «The technical tools of decision making». En N. J. BOYAN (ed.). Handbook of research on educational administration (525-568). Longman, Nueva York.

March, G. H. y Simon, H. A. (1981). Teoría de la organización. Ariel, Buenos Aires.

Medina Rubio, R. (1982). Política y legislación educativa. U.N.E.D., Madrid.

- (1983). «Educación y pluralismo político-administrativo». Revista Española de Pedagogía. 49 (161), 463-486.

- (1986). «Política educativa» y «Sistema educativo». En G. GómEZ DACAL (Coord.). Administración educativa. Diccionario de Ciencias de la Educación. 354-357; y, 394-396. Anaya, Madrid.

- (Coord.) (1989). «La educación en el Estado de las Autonomías». Ponencia presentada al VIII Seminario Interuniversitario de Teoría de la educación: La educación multicultural en el Estado de las Autonomías. Tomo I. Departamento de Teoría e Historia de la Educación de la Universidad del País Vasco, San Sebastián (material policopiado).

Mitchel, D. (1988). «Educational politics and policy: The State level». En N. J. BoYAN (ed.). Handbook of research on educational administration. 453-466. Longman, Nueva York.

Muguerza, J. (1970). «'Es' y 'debe'. En torno a la lógica de la falacia naturalista. En Teoría y sociedad. 141-175.

Peters, R. S. (1974). Psychology and ethical development. G. Allen and Unwin, Londres.

- (1979). Ethics and education. G. Allen and Unwin, Londres.

PÉrez Juste, R. (1993). «Evaluación de las adaptaciones curriculares». Revista de Ciencias de la Educación (153), 51-69.

Polanyi, M. (1964). Science, faith and society. University of Chicago Press, Chicago.

Popper, K. (1967). La sociedad abierta y sus enemigos. Paidós, Buenos Aires.

- (1974). Conocimiento objetivo. Tecnos, Madrid.

- (1977). La lógica de la investigación científica. Tecnos, Madrid.

Quintanilla, M. A. (1981). A favor de la razón. Taurus, Madrid.

RADNITZKY, G. (1980). «What limits do technology and science have?». Crítica. 16 (35), 15-54. México.

- (1982). «De la fundamentación de teorías a la preferencia fundamentada de teorías». En G. RADNITZKY et al. Progreso y racionalidad en la ciencia (283-323). Alianza Universidad, Madrid.

- (1984). «La tesis de que la ciencia es una empresa libre de valores: Ciencia, ética y política». En P. FEyERABEND, G. RADNITZKY et al. Estructura y desarrollo de la ciencia. Alianza Universidad, Madrid.

RodRíGuez Martínez, A. (1989). Conocimiento de la Educación, función pedagógica y política educativa. Tesis doctoral, Facultad de Filosofía y Ciencias de la Educación de la Universidad de Santiago de Compostela (editada en microficha por el Servicio de Publicaciones e Intercambio Científico de la Universidad de Santiago de Compostela en 1990 con el n ${ }^{\circ} 82$ ). Santiago de Compostela. 
Russel, B. (1977). El conocimiento de lo humano. Tauros, Madrid.

SANVISENS, A. (1986). «Teoría cibernética de la acción». En la obra conjunta Tecnología y Educación. (33-51). CEAC, Barcelona.

SCHEUERL, H. (1984). «Sobre la cuestión de la fundamentación de las decisiones pedagógicas». Educación (39), 78-94. Tubinga.

SPAEY, J. et al. (1970). El desarrollo de la ciencia. Ensayo sobre la aparición y organización de la política científica de los estados. Ministerio de Educación y Ciencia, Madrid.

TAYLOR, CH. (1976). «La neutralidad de la ciencia política». En A. RYAN. La filosofía de la explicación social (218-166). Fondo de Cultura Económica, México.

THOMAS, L. G. (1972). «A model for making and testing value judgements». En L. G. THOMAS (ed.). Philosophical redirection of educational research. $1^{\text {a }}$ Yearbook of the National Society for the Study of Education. $1^{a}$ parte. University of Chicago.

TISSEltus, A. y NiLSSON, S. (eds.) (1971). The place o value in a world of facts. J. Wiley, Nueva York.

TORROBA, I. (1993). «Programas educativos: indicadores para evaluar aprendizajes significativos». Revista de Ciencias de la Educación (153), 105-121.

TOULMIN, S. (1974). «Rationality and science discovery». En R. S. COHEN y M. W. WARTOFSKY (eds.). Boston studies in the philosophy of science (387-406). Vol. XX. Dordrecht.

- (1977). La comprensión humana. El uso colectivo y la evolución de los conceptos. Alianza Universidad, Madrid.

- (1979). El puesto de la razón en la ética. Alianza Universidad, Madrid.

- (1980). The uses of arguments. University Press, Cambridge.

TOULMIN, S.; RIEKE, R. y JANIK, A. (1979). Introduction to reasoning. Collier-MacMillan, Londres.

TOURIÑÁN, J. M. (1983). «El educador y su responsabilidad ante la legislación en una sociedad pluralista: Estudio de un caso». Bordón. 35 (249), 379-404.

- (1984). «Delimitación de la intervención educativa como acción». Revista Española de Pedagogía. 42 (163), 79-91.

- (1987). La Educación como objeto de conocimiento. Teoría de la Educación. Anaya, Madrid.

- (1987a). Estatuto del profesorado. Función pedagógica y alternativas de formación. Escuela Española, Madrid.

- (1989). «Teoría de la Educación: Identificación de la asignatura y competencia disciplinar». Revista de Ciencias de la Educación. 35 (137), 7-36.

- (1989a). «Las finalidades de la educación: Análisis teórico». En J. M. EsTEve (ed.). Objetivos y contenidos de la educación para los años noventa (15-36). Universidad de Málaga, Málaga.

- (1989b). «Bilingüismo e intervención pedagóxica: A función do profesional da educación». En X. CAJIDE VAL (dir.). Modelos de ensino bilingüe axeitados a realidade galega (15-35). Xunta de Galicia-Consellería de Educación, Santiago de Compostela.

TOURIÑÁN, J. M. y RodRÍGUEZ, A. (1993). «La significación del conocimiento de la educación». En prensa (Revista Portuguesa de Filosofia. Braga).

TURIEL, E. (1984). El desarrollo del conocimiento social. Moralidad y convención. Debate, Madrid.

WHEELER, D. K. (1976). El desarrollo del currículum escolar. Santillana, Madrid.

WhITE, D. J. (1979). Teoría de la decisión. Alianza Universidad, Madrid. 